\title{
ADHESION OF BIOCOMPATIBLE TiNb COATING
}

\author{
Tomas Kolegar ${ }^{a, *}$, Martin MatouseK $^{a}$, Monika Vilemova $^{b}$, \\ VLADIMIR STARY ${ }^{a}$
}

${ }^{a}$ Faculty of Mechanical Engineering, Department of Material Engineering, Czech Technical University in Prague, Charles square 13, 12135 Prague, Czech Republic

${ }^{b}$ Institute of Plasma Physics AS CR, v.v.i.

* corresponding author: tomas.kolegar@fs.cvut.cz

Abstract. Preparation of a coating with a high quality requires good adhesion of the film to the substrate. The paper deals with the adhesion of biocompatible TiNb coating with different base materials. Several materials such as titanium CP grade 2, titanium alloys Ti6Al4V and stainless steel AISI 316L were measured. Testing samples were made in the shape of small discs. Those samples were coated with a TiNb layer by using the PVD method (magnetron sputtering). Onto the measured layer of TiNb an assistant cylinder was stuck using a high strength epoxy adhesive E1100S. The sample with the assistant cylinder was fixed into a special fixture and the whole assembly underwent pull-off testing for adhesion. The main result of this experiment was determining the strength needed to peel the layer and morphology and size of the breakaway. As a result, we will be able to determine the best base material and conditions where the coating will be remain intact with the base material.

Keywords: PVD coating, Adhesion, Biocompatible materials, Pull-off test, Titanium, Niobium.

\section{INTRODUCTION}

Today's civilized society brings human kind many simplifications for numerous activities in every day life. Due to this comfort more civilization illnesses appear, such as obesity, cancer, atherosclerosis, heart attack and of course musculoskeletal diseases including joints and tendons, but also chronic stress and sports injuries. High life expectancy on other hand causes faster aging of tissue and makes surgery of hip, shoulder and other joints necessary. One solution to help with this this health problem is the utilization of implants.

Nowadays, commonly used implants are made of lower quality material like stainless steel and these implants are coated with a high quality biocompatible material such as TiNb and also other titanium alloys. The most important property of the coating is its adhesion to the base material. The main quality of the parameters for adhesion are the substrate structural properties, purity and surface condition at the time of coating formation, the value of the kinetic energy of falling atoms and ions to the surface, and also the forming a coating on the support surface and the other deposition parameters. According to G. Rosenman, the minimum adhesion strength of biocompatible coating to the substrate is $15 \mathrm{MPa}$ [1] and cells have better conditions for adhesion, growth and their establishment in the living body. The goal of this experiment is to verify if the coating is capable of withstanding the strain which can be found in the human body. Each human body and conditions inside are very individual and results depend on many factors [2].

\section{Materials And Procedure}

For the experiment three base materials were used. Titanium CP grade 2, Ti6Al4V and stainless steel AISI 316L. Chemical composition of these materials is shown in table 1, 2 and $3[3]$.

Experimental samples (discs of diameter $14 \mathrm{~mm}$ and $4 \mathrm{~mm}$ thickness) were coated with $\mathrm{TiNb}$ (61 wt \% of $\mathrm{Ti}$ and 39 wt $\%$ of $\mathrm{Nb})$. The PVD magnetron sputtering method was used [4. Final thickness of the coating was measured by Calotest (CSM, Switzerland) and it was $2.4 \pm 0.1 \mu \mathrm{m}$. The screw according to DIN 931 with a $10 \mathrm{~mm}$ metric thread was used as the assistant cylinder. These two parts were glued together with high strength epoxy adhesive E1100S with a minimum ultimate tensile strength $70 \mathrm{MPa}$. The glue was cured in a furnace for 1 hour at $140{ }^{\circ} \mathrm{C}$. The pull-off test performed on the available samples was according to EN ISO 4624:2003 [5, 6].

Table 4 presents the measured parameters of the experiment, especially the force when the tested sample was broken. Ultimate tensile strength and the average value were measured.

\section{Results of the EXPERIMENT (Morphology and Tensile StREnGTh)}

Results of the experiments can be seen in figures 1,2 and 3

Note: The most suitable sample was chosen.

Black spot indicates detachment of coating. 


\begin{tabular}{ccccccccccc}
\hline $\mathrm{C}$ & $\mathrm{N}$ & $\mathrm{Mn}$ & $\mathrm{P}$ & $\mathrm{S}$ & $\mathrm{Cr}$ & $\mathrm{Mo}$ & $\mathrm{Ni}$ & $\mathrm{Cu}$ & $\mathrm{Si}$ & $\mathrm{Fe}$ \\
\hline 0.022 & 0.094 & 1.75 & 0.021 & 0.001 & 17.18 & 2.71 & 14.1 & 0.06 & 0.35 & rest \\
\hline
\end{tabular}

TABle 1. Chemical composition of AISI 316L [wt \%]

\begin{tabular}{ccccccccccc}
\hline $\mathrm{C}$ & $\mathrm{N}$ & $\mathrm{O}$ & $\mathrm{H}$ & $\mathrm{Fe}$ & $\mathrm{Al}$ & $\mathrm{V}$ & $\mathrm{Ni}$ & $\mathrm{Mo}$ & Other & $\mathrm{Ti}$ \\
\hline 0.08 & 0.03 & 0.25 & 0.0125 & 0.3 & - & - & - & - & - & rest \\
\hline
\end{tabular}

TABle 2. Chemical composition of Titanium CP grade 2 [wt \%]

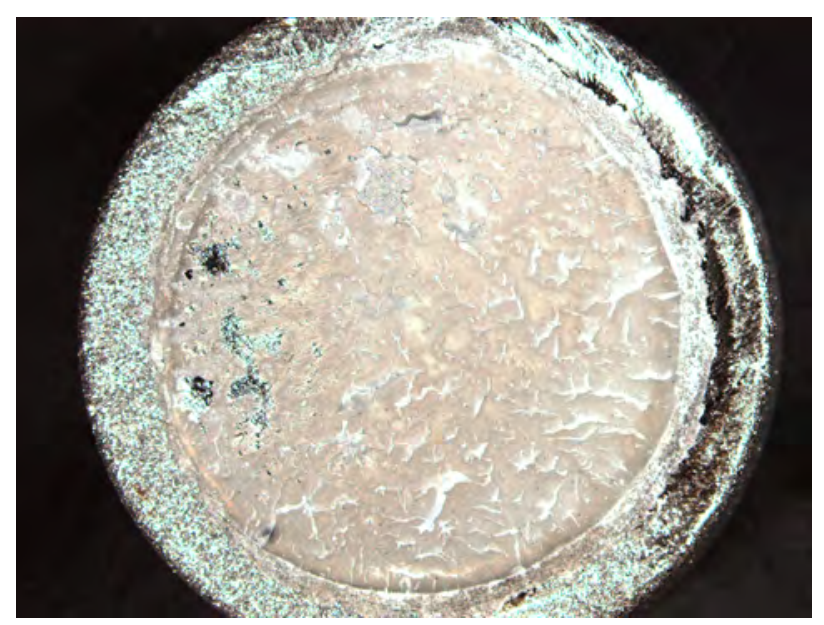

Figure 1. Stainless steel AISI 316L.

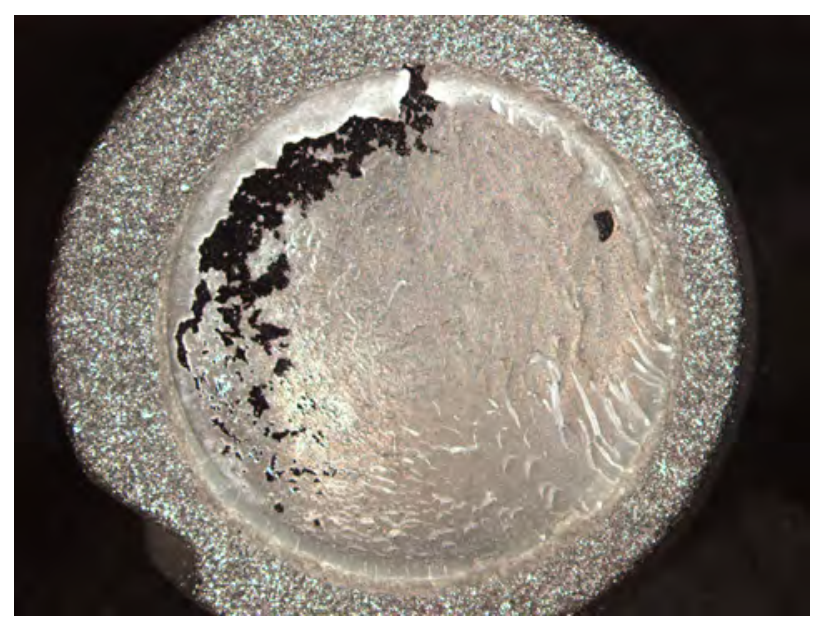

Figure 2. Titanium CP grade 2.

\section{Conclusions}

- Average UTS on Fe-material was measured (22.48 $\mathrm{MPa})$.

$\triangleright$ Coating stayed on sample.

- Average UTS on Ti-material was measured (19.30 $\mathrm{MPa})$.

$\triangleright$ Coating was partially removed.

- Average UTS on Ti6Al4V-material was measured (34.27 MPa).

$\triangleright$ Large part of coating was removed.

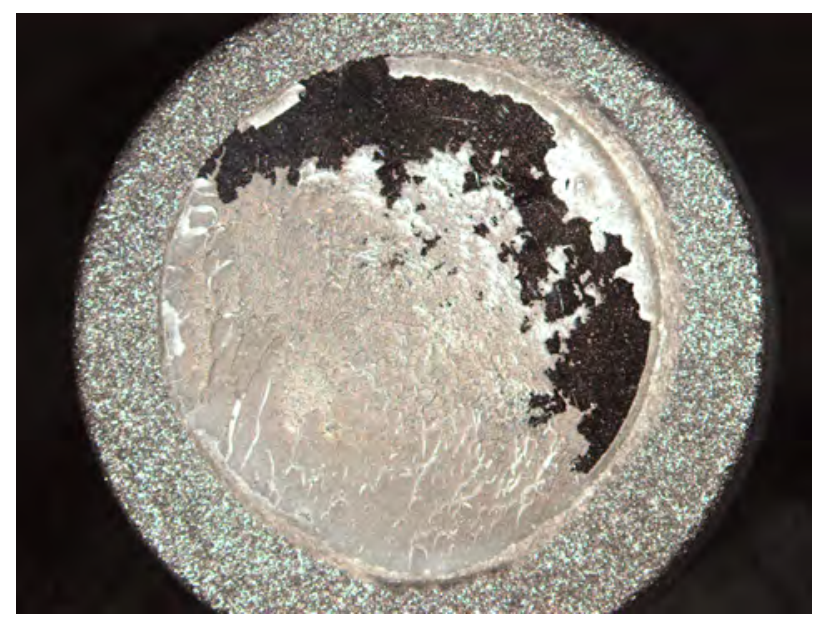

Figure 3. Titanium alloys Ti6Al4V.

Ultimate tensile strength of epoxy adhesive E1100S specified by manufacturer is $70 \mathrm{MPa}$. In the experiment, we achieve $34 \mathrm{MPa}$ in the best result (Ti6Al4V) while all three testing materials should withstand more than $15 \mathrm{MPa}$ which is the minimum adhesion strength according to G. Rosenman [1]. Each human body is very individual and we must be sure that implants withstand all the processes in the human body. High values of UTS approaching the values set up by manufacturer are more than is required. Generally, on a surface with high roughness the adhesion is also higher. Further experiments will involve changing parameters of the surface roughness, combination of epoxy adhesion and film adhesion. An ultimate tensile strength of coating at least higher than $50 \mathrm{MPa}$ should be achieved.

\section{LIST OF SYMBOLS}

$F \quad$ Force [N]

$R a$ Roughness average $[\mu \mathrm{m}]$

UTS Ultimate tensile strength [MPa]

\section{ACKNOWLEDGEMEnTs}

This work was supported by project LO1207, Program NPU1, from the Ministry of Education, Youth and Sports of the Czech Republic and by Czech Science Foundation project No. 15-01558S. 


\begin{tabular}{ccccccccccc}
\hline $\mathrm{C}$ & $\mathrm{N}$ & $\mathrm{O}$ & $\mathrm{H}$ & $\mathrm{Fe}$ & $\mathrm{Al}$ & $\mathrm{V}$ & $\mathrm{Ni}$ & $\mathrm{Mo}$ & Other & $\mathrm{Ti}$ \\
\hline 0.08 & 0.05 & 0.13 & 0.012 & 0.25 & 6.5 & 4.5 & - & - & - & rest \\
\hline
\end{tabular}

TABle 3. Chemical composition of Ti6Al4V [wt \%]

\begin{tabular}{|c|c|c|c|c|c|c|}
\hline & Sample & $\begin{array}{l}\mathrm{F} \\
{[\mathrm{N}]}\end{array}$ & $\begin{array}{c}\mathrm{Ra} \\
{[\mu \mathrm{m}]}\end{array}$ & $\begin{array}{l}\text { UTS } \\
{[\mathrm{MPa}]}\end{array}$ & $\begin{array}{c}\text { Average UTS } \\
{[\mathrm{MPa}]}\end{array}$ & $\begin{array}{c}\text { Stand. Deviation } \\
{[\mathrm{MPa}]}\end{array}$ \\
\hline \multirow{3}{*}{ AISI 316L } & 1 & 1540 & \multirow{9}{*}{$0.06 \pm 0.01$} & 19.62 & \multirow{3}{*}{22.48} & \multirow{3}{*}{2.59} \\
\hline & 2 & 1950 & & 24.84 & & \\
\hline & 3 & 1990 & & 25.35 & & \\
\hline \multirow{3}{*}{$\mathrm{Ti}(\mathrm{CP} 2)$} & 1 & 1040 & & 13.25 & \multirow{3}{*}{19.30} & \multirow{3}{*}{4.94} \\
\hline & 2 & 1490 & & 18.98 & & \\
\hline & 3 & 1990 & & 25.35 & & \\
\hline \multirow{3}{*}{ Ti6Al4V } & 1 & 3160 & & 40.25 & \multirow{3}{*}{34.27} & \multirow{3}{*}{4.90} \\
\hline & 2 & 2630 & & 33.50 & & \\
\hline & 3 & 2220 & & 28.28 & & \\
\hline
\end{tabular}

TABLE 4. Table of measured parameters

\section{REFERENCES}

[1] N. Eliaz, O. Ritman-Hertz, D. Aronov, et al. The effect of surface treatments on the adhesion of electrochemically deposited hydroxyapatite coating to titanium and on its interaction with cells and bacteria. Journal of Materials Science: Materials in Medicine 22(7):1741-1752, 2011. DOI:10.1007/s10856-011-4355-y

[2] E. Eisenbarth, D. Velten, M. Müller, et al.

Biocompatibility of $\beta$-stabilizing elements of titanium alloys. Biomaterials 25(26):5705 - 5713, 2004. DOI:http://doi.org/10.1016/j.biomaterials.2004.01.021.

[3] S. Guo, J. Zhang, X. Cheng, X. Zhao. A metastable $\beta$-type Ti-Nb binary alloy with low modulus and high strength. Journal of Alloys and Compounds 644:411 415,2015

DOI:http://doi.org/10.1016/j.jallcom.2015.05.071
[4] K.-T. K. Chiang, R. Wei. Growth morphology and corrosion resistance of magnetron sputtered $\mathrm{Cr}$ films. Surface and Coatings Technology 206(7):1660 - 1665, 2011. DOI:http://doi.org/10.1016/j.surfcoat.2011.09.020

[5] B. Jönsson, S. Hogmark. Hardness measurements of thin films. Thin Solid Films 114(3):257 - 269, 1984. DOI:http://dx.doi.org/10.1016/0040-6090(84)90123-8.

[6] X. Dai, A. Zhou, L. Feng, et al. Molybdenum thin films with low resistivity and superior adhesion deposited by radio-frequency magnetron sputtering at elevated temperature. Thin Solid Films 567:64 - 71, 2014. DOI:http://doi.org/10.1016/j.tsf.2014.07.043 